\title{
Dynamics of Long-Life Assets: The Editors' Intro
}

\author{
Göran Granholm, Stefan N. Grösser and Arcadio Reyes-Lecuona
}

\begin{abstract}
The manufacturing industry is changing. Driven by a number of concurrent trends, including economic and political development, technological breakthroughs and social connectivity, the impacts on industry in general are fundamental. Companies need to find ways to adapt to this change in collaboration with actors across their value networks. For long-life industrial assets, i.e., industrial product-service systems, both economically and environmentally sustainable solutions become an imperative supported by new business models-based collaborative value creation. In an EU-funded research project twenty organisations including three research institutes, four universities and thirteen companies studied, developed and demonstrated ways to deal with the dynamics of long-life assets. The main findings are summarised in this book. This chapter provides a brief introduction to the topic and presents the structure of the rest of this book.
\end{abstract}

Keywords Digitalisation - Business model • Industrial product-services system • Technology adaptation $\cdot$ Asset $\cdot$ Dynamics

\footnotetext{
G. Granholm ( $₫)$

VTT Technical Research Centre of Finland Ltd., Espoo, Finland e-mail: goran.granholm@vtt.fi

S.N. Grösser

Institute for Corporate Development, Bern University of Applied Sciences,

Bern, Switzerland

e-mail: stefan.groesser@bfh.ch
}

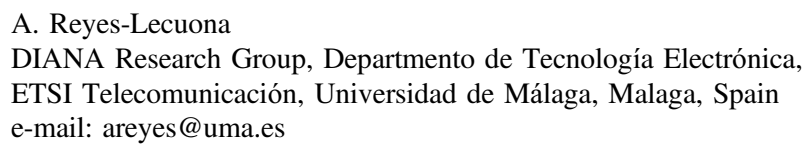

A. Reyes-Lecuona

DIANA Research Group, Departmento de Tecnología Electrónica,

ETSI Telecomunicación, Universidad de Málaga, Malaga, Spain

e-mail: areyes@uma.es 


\section{Introduction}

Digitalisation transforms industries globally. Companies, products and people have become increasingly connected and constantly accessible regardless of time or location. Combined with new technology innovations this gives rise to completely new products and services capable of adapting to specific customer needs. However, the demand for fast delivery of personalised solutions cannot be met by traditional, rigid supply chain structures. Instead, agile supply networks of highly specialised companies are emerging, adopting new, innovative business models. The growing technological complexity and speed of development requires a high level of specialisation. This emphasizes the need for collaboration on research and development between relevant actors to complement gaps in knowledge and innovation capacity, and to share risk and resources, especially in small and medium sized companies (Romero and Molina 2011). In a recent survey (KPMG 2015), more than three-quarters of the respondents said that partnerships will form the basis of innovation for their company.

In search of efficiency and flexibility, firms are driven to both form vertical and horizontal alliances, which in turn require a more strategic approach to integration and networking (Rothwell 1994). This extends to new ways of sharing revenues through the value network. Enabled by the digital transformation, a new performance economy is emerging, shifting the focus from selling products and services to selling measurable outcome and results, a change that will redefine the base of competition and industry structures (World Economic Forum 2015). Technology platforms and ecosystems of partnerships will take over large parts of the current business in the near future. For instance, the emerging Industry 4.0 supplier ecosystem is expected to reach $€ 420$ billion in value and ICT-based services are expected to account for more than $75 \%$ of all industrial services, amounting to nearly $€ 17.5$ billion in revenues by 2020 (Frost and Sullivan 2015). Knowledge has been seen as an asset for coping with the increasing complexity of inter-organisational value chains. Thus, continuous learning within and between organisations has become a key strategic requirement for building and sustaining future competitiveness (Bessant et al. 2003).

In parallel with technological development there is a growing concern about human impact on the environment and the limits of the global ecological capacity. This has led to political decisions and global agreements aiming at reducing ecological footprints. Research into key enabling technologies, such as new materials and manufacturing technologies, help reduce ecological footprints and comply with tightening regulations to, for example, reduce global warming or the use of non-renewable resources. Closed-loop life-cycles and circular economy business models appear as a viable solution to reduce environmental impacts. The European Commission has adopted an ambitious Circular Economy Package, which includes revised legislative proposals to stimulate Europe's transition towards a circular economy (European Commision 2015). A prerequisite for circular life-cycle models is a shift from a business logic based on products as the main bearer value to models 
based on life-cycle value shared through the value network (Tukker 2013). This requires new forms of collaboration and focusing on product based services to create end user benefit.

An industrial product-service system (IPSS or IPS ${ }^{2}$ ) is an integrated product and service offering that delivers values in industrial applications, characterized by the integrated and mutually determined planning, development, provision and use of product and service shares (Meier et al. 2010). The majority of companies that have adopted the concept of industrial product-service systems offer the use of a product, but not the ownership of the respective product (Guidat et al. 2014). In business models where user value is based on system outcome instead of ownership OEMs are more prone to design for total life-cycle cost, which in turn tend to lead to longer life spans and focus on sustainable solutions (Sundin and Bras 2005). This includes better end-of-life management but also the dynamic adoption of changing customer demands and improved provider abilities along the life cycle (Meier et al. 2010).

High-investment industrial product-service systems face new challenges in this dynamic and highly competitive business environment. Due to high initial investment costs such systems are usually designed for relatively long life spans. Sustainability goals call for further extension of system life-cycles. At the same time personalised, targeted solutions and improvements based on new technologies push in the opposite direction (EFFRA 2013). Extending systems life-cycles require careful planning and close collaboration with end-users to ensure both ecological, economic and technical sustainability. Processes for continuously improving IPSS need to match the specific IPSS characteristics and value network structures (Schweitzer and Aurich 2010). Continuous performance monitoring and information exchange processes need to be established case by case.

Innovation has been identified as the most important asset for creating business value. Focus has already shifted from the own R\&D department as the main source of innovation to include other in-house functions, and is now extending beyond corporate borders to involve other actors of the value chain, including end-users and other stakeholders. In the future, innovation will depend heavily on emerging ecosystems. This, again, requires new forms of collaboration, which includes also competing companies.

Efficient strategies must be developed to upgrade legacy product-service systems to meet new requirements and enable economically and ecologically viable system life-cycles. This requires new ways of collaboration and a comprehensive approach building on the combined knowledge of the actor network, exchange of knowledge between researchers and practitioners, and learning across industry domains. 


\section{Future-Proofing Industrial Product-Service Systems}

In July 2013, twenty organisations representing research and industry across Europe signed an agreement with the European Commission to undertake a research project focusing on upgrading of capital intensive product-services to meet future demands of efficiency, performance and fitness for purpose. The project called "Innovative continuous upgrades of high investment product-services" was funded under the European Commission's seventh Framework Program theme [FoF.NMP.2013-5] Innovative design of personalised product-services and of their production processes based on collaborative environments, short named Use-it-Wisely, and was part of the Factories of the Future public-private partnership in 2009. Public-private partnerships (or PPPs) were launched by the European Commission (executive of European Union or EU) as part of European Economic Recovery Plan presented in 2008.

The general objectives of the Factories of the Future PPP are to (EFFRA 2013):

- increase EU industrial competitiveness and sustainability in a global world through R\&I activities for the timely development of new knowledge-based production technologies and systems;

- promote EU 2020 targets of a smart, green and inclusive economy;

- support EU industrial policy targets (EC industrial policy communication October 2012); and

- underpin EU trade and investment policy.

To meet these targets, the Use-it-Wisely (UIW) project set out to develop tools and models to help industry deal with change. The project focuses on continual improvement of products and services through a continuous upgrade activity based on a comprehensive approach involving multiple actors in a collaborative effort to improve product and services through small innovative upgrade increments.

The project targets industries dealing with high-investment products and services in general, not limited to any particular industry sector. The definition of 'high-investment' is therefore more linked to the rate of return than on the absolute value of the initial investment. A common characteristic of such systems is therefore a relative long operational life-cycle. During their life such systems must be maintained and regularly upgraded to meet requirements that were not known or anticipated when they were first designed.

Tools and methods developed in the project were implemented and tested in six separate pilot cases representing different industries: power turbines inspection, machinery, space mission, manufacturing lines, shipping and office furniture. 


\section{Content of the Book}

The book is organised in three main parts. Part I gives an introduction to the specific challenge addressed in the book (Chapter "The Challenge") and presents the foundations of the UIW-approach (Chapter "The Use-it-Wisely (UIW) Approach"). Part II goes into more detail in some of the key topics of the approach: innovation management (Chapter "Innovation Management with an Emphasis on Co-creation"), systems and complexity management (Chapter "Complexity Management and System Dynamics Thinking"), environmental impact (Chapter "Managing the Life Cycle To Reduce Environmental Impacts"), virtual reality (Chapter "Virtual Reality and 3D Imaging to Support Collaborative Decision Making for Adaptation of LongLife Assets"), human-centred design (Chapter "Operator-Oriented Product and Production Process Design for Manufacturing, Maintenance and Upgrading”), virtual communities (Chapter "Fostering a Community of Practice for Industrial Processes"), and system modelling (Chapter "Extending the System Model"). Part III describes six actual use cases where tools and technologies have been implemented and tested in the six different industry clusters: Service inspections power plant turbines (Chapter "Collaborative Management of Inspection Results in Power Plant Turbines"), upgrade business models of mobile rock crushers (Chapter "Rock Crusher Upgrade Business from a PLM Perspective"), collaborative information management in space systems development (Chapter "Space Systems Development"), adaptation of high variant automotive production systems (Chapter "Adaptation of High-Variant Automotive Production System Using a Collaborative Approach"), actor collaboration in maritime passenger vessel design (Chapter "Supporting the small-to-medium vessel industry"), and sustainable furniture business based on circular economy (Chapter "Sustainable Furniture That Grows with End-Users"). Finally, different upgrade business models defined based on an analysis of the pilot cases (Chapter "Comparing Industrial Cluster Cases to Define Upgrade Business Models for a Circular Economy").

The chapters can be read independently but for understanding the concept of the approach is advisable to first read Sect. 1. References to relevant chapters inside the book will be given when needed. The book is linked to online resources maintained by the UIW-virtual community accessible at http://use-it-wisely.eu.

Acknowledgements The research leading to these results has received funding from the European Union's Seventh Framework Programme (FP7/2007-2013) under grant agreement no 609027 . The results are based on close collaboration between the 20 partners of the UIW-research project. 


\section{References}

Bessant, J., Kaplinsky, R., \& Lamming, R. (2003). Putting supply chain learning into practice. International Journal of Operations \& Production Management, 23(2), 167-184.

EFFRA. (2013). Factories of the future: Multi-annual roadmap for the contractual PPP under Horizon 2020. Publications Office of the European Union.

European Commision. (2015). Closing the loop-An EU action plan for the circular economy. Communication from the Commission, COM (2015) 614 final.

Frost \& Sullivan. (2015). Industry 4.0 business ecosystem-Decoding the new normal.

Guidat, T., Barquet, A. P., Widera, H., Rozenfeld, H., \& Seliger, G. (2014). Guidelines for the definition of innovative industrial product-service systems (PSS) business models for remanufacturing. Procedia CIRP, 16, 193-198.

KPMG. (2015). Global Manufacturing Outlook: Preparing for battle - Manufacturers get ready for transformation. Retrieved from https://home.kpmg.com/xx/en/home/insights/2015/05/ preparing-for-battle.html

Meier, H., Roy, R., \& Seliger, G. (2010). Industrial product-service systems-IPS2. CIRP Annals-Manufacturing Technology, 59(2), 607-627.

Romero, D., \& Molina, A. (2011). Collaborative networked organisations and customer communities: Value co-creation and co-innovation in the networking era. Production Planning \& Control, 22(5-6), 447-472.

Rothwell, R. (1994). Towards the fifth-generation innovation process. International Marketing Review, 11(1), 7-31. http://doi.org/10.1108/02651339410057491

Schweitzer, E., \& Aurich, J. C. (2010). Continuous improvement of industrial product-service systems. CIRP Journal of Manufacturing Science and Technology, 3(2), 158-164.

Sundin, E., \& Bras, B. (2005). Making functional sales environmentally and economically beneficial through product remanufacturing. Journal of Cleaner Production, 13(9), 913-925.

Tukker, A. (2013). Product services for a resource-efficient and circular economy-A review. Journal of Cleaner Production, 97, 76-91.

World Economic Forum. (2015). Industrial internet of things: Unleashing the potential of connected products and services. Retrieved from http://www.weforum.org/reports/industrialinternet-things.

Open Access This chapter is licensed under the terms of the Creative Commons Attribution-NonCommercial 4.0 International License (http://creativecommons.org/licenses/by-nc/ 4.0/), which permits any noncommercial use, sharing, adaptation, distribution and reproduction in any medium or format, as long as you give appropriate credit to the original author(s) and the source, provide a link to the Creative Commons license and indicate if changes were made.

The images or other third party material in this chapter are included in the chapter's Creative Commons license, unless indicated otherwise in a credit line to the material. If material is not included in the chapter's Creative Commons license and your intended use is not permitted by statutory regulation or exceeds the permitted use, you will need to obtain permission directly from the copyright holder.

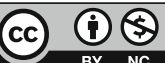

